\title{
ARTICLE
}

Clinical Study

\section{The prognostic value of systemic inflammation in patients undergoing surgery for colon cancer: comparison of composite ratios and cumulative scores}

\author{
Ross D Dolan ${ }^{1}$, Stephen T McSorley $\mathbb{D D}^{1}$, James H Park ${ }^{1}$, David G Watt ${ }^{1}$, Campbell S Roxburgh ${ }^{1}$, Paul G Horgan ${ }^{1}$ and Donald C McMillan ${ }^{1}$
}

INTRODUCTION: The systemic inflammatory response has been proven to have a prognostic value. There are two methods of assessing the systemic inflammatory response composite ratios $(\mathrm{R})$ and cumulative scores $(\mathrm{S})$. The aim of this study was to compare the prognostic value of ratios and scores in patients undergoing surgery for colon cancer.

METHODS: Patients were identified prospectively in a single surgical unit. Preoperative neutrophil (N), lymphocyte (L), monocyte $(\mathrm{M})$ and platelet $(\mathrm{P})$ counts, CRP (C) and albumin (A) levels were recorded. The relationship between composite ratios neutrophil-lymphocyte ratio (NLR), platelet-lymphocyte ratio (PLR), lymphocyte-monocyte ratio (LMR), C-reactive protein albumin ratio (CAR) and the cumulative scores neutrophil- lymphocyte score (NLS), platelet-lymphocyte score (PLS), lymphocyte-monocyte score (LMS), neutrophil- platelet score (NPS), modified Glasgow prognostic score (mGPS) and clinicopathological characteristics, cancer-specific survival (CSS) and overall survival (OS), were examined.

RESULTS: A total of 801 patients were examined. When adjusted for tumour node metastasis (TNM) stage, NLR $>5$ ( $p<0.001)$, NLS $(p<0.01)$, PLS $(p<0.001)$, LMR $<2.4(p<0.001)$, LMS $(p<0.001)$, NPS $(p<0.001)$, CAR $>0.22(p<0.001)$ and mGPS $(p<0.001)$ were significantly associated with CSS. In patients undergoing elective surgery $(n=689)$, the majority of the composite ratios/scores correlated with age $(p<0.01)$, BMI $(p<0.01)$, T stage $(p<0.01)$, venous invasion $(p<0.01)$ and peritoneal involvement $(p<0.01)$. When NPS (myeloid) and mGPS (liver) were directly compared, their relationship with CSS and OS was similar.

CONCLUSIONS: Both composite ratios and cumulative scores had prognostic value, independent of TNM stage, in patients with colon cancer. However, cumulative scores, based on normal reference ranges, are simpler and more consistent for clinical use.

British Journal of Cancer https://doi.org/10.1038/s41416-018-0095-9

\section{INTRODUCTION}

Colorectal cancer is the fourth most common cancer in the United Kingdom and the second most common cause of cancer death. ${ }^{1}$ Despite death rates from colorectal cancer falling by approximately $14 \%$ over the last decade, approximately $40 \%$ of those diagnosed will die from their colorectal cancer. Surgery remains the primary modality of cure in these patients and therefore there is a continuing interest in factors that will effectively identify patients at high risk of dying from their disease following potentially curative surgery.

Over the last decade or so it has become clear that markers of the systemic inflammatory response are clinically useful to identify patients at high risk of tumour progression in a variety of common solid tumours, in particular lung and gastrointestinal cancer. ${ }^{2,3}$ These markers of the systemic inflammatory response are usually based around composite ratios or cumulative scores of different circulating white blood cells or acute phase proteins representing the systemic responses of two different organs, lymphoid/myeloid tissue and liver, respectively (Table 1). There have been two main approaches to the formation of these prognostic scores. One approach is to take the ratio of different white blood cells and then apply a prognostic threshold to the ratio such that outcome is effectively stratified. The most repeatedly validated example of this approach is the neutrophil-lymphocyte ratio (NLR) based on the ratio of circulating neutrophil and lymphocyte counts (Table 1). ${ }^{2,3}$ Other validated examples are the platelet-lymphocyte ratio (PLR) based on the ratio of circulating platelet and lymphocyte counts (Table 1) and the lymphocyte-monocyte score (LMR) based on the ratio of circulating lymphocyte and monocyte counts (Table 1). ${ }^{2,3}$ Also, recently a similar approach has been applied to the acute phase proteins, C-reactive protein and albumin, and C-reactive protein albumin ratio (CAR) has been recently validated (Table 1). ${ }^{2,3}$ Although it is clear that the above ratios have prognostic value, a disadvantage of the ratio approach is that, depending on the threshold used, an abnormal ratio may be defined with one or both markers having a normal value.

A simpler approach is the cumulative prognostic score, where markers of the systemic inflammatory response are defined as normal or as abnormal based on their laboratory reference ranges such that two markers with normal values score lowest and have the best outcomes and two markers with abnormal values score highest and have the poorest outcomes. The most widely validated example of this approach is the Glasgow prognostic score (mGPS) based on the acute phase proteins,

\footnotetext{
${ }^{1}$ Academic Unit of Surgery, School of Medicine, Glasgow Royal Infirmary, University of Glasgow, Glasgow, UK
}

Correspondence: Ross D Dolan (Ross.Dolan@glasgow.ac.uk)

Received: 10 January 2018 Revised: 3 April 2018 Accepted: 6 April 2018

Published online: 23 May 2018 
Table 1. Systemic inflammation-based prognostic ratios and scores

Ratio/score
NLR
Neutrophil count: lymphocyte count
Neutrophil count: lymphocyte count
Neutrophil count: lymphocyte count
NLS
Neutrophil count $\leq 7.5 \times 10^{9} /$ I and lymphocyte count $\geq 1.5 \times 10^{9} / I$
Neutrophil count $>7.5 \times 10^{9} /$ I and lymphocyte count $\geq 1.5 \times 10^{9} / I$
Neutrophil count $\leq 7.5 \times 10^{9} /$ I and lymphocyte count $<1.5 \times 10^{9} / /$
Neutrophil count $>7.5 \times 10^{9} / I$ and lymphocyte count $<1.5 \times 10^{9} / /$
PLR

PLR

Platelet count: lymphocyte count $\quad \leq 150$

Platelet count: lymphocyte count $\quad>150$

PLS

Platelet count $\leq 400 \times 10^{9} / \mathrm{I}$ and lymphocyte count $\geq 1.5 \times 10^{9} / \mathrm{I}$

Platelet count $>400 \times 10^{9} / \mathrm{I}$ and lymphocyte count $\geq 1.5 \times 10^{9} / \mathrm{I}$

Platelet count $\leq 400 \times 10^{9} / \mathrm{l}$ and lymphocyte count $<1.5 \times 10^{9} / \mathrm{I}$

Platelet count $>400 \times 10^{9} / \mathrm{I}$ and lymphocyte count $<1.5 \times 10^{9} / \mathrm{I}$ LMR

Lymphocyte count: monocyte count

Lymphocyte count: monocyte count

Ratio/score

$\leq 3$

3-5

$>5$

0

1

1

2

0

1

1

2

$\geq 2.40$

$<2.40$

LMS

Lymphocyte count $\geq 1.5 \times 10^{9} / \mathrm{I}$ and monocyte count $\leq 0.80 \times 10^{9} / \mathrm{I}$

Lymphocyte count $\geq 1.5 \times 10^{9} / \mathrm{I}$ and monocyte count $\leq 0.80 \times 10^{9} / \mathrm{I}$

Lymphocyte count $<1.5 \times 10^{9} / \mathrm{I}$ and monocyte count $>0.80 \times 10^{9} / \mathrm{I}$

Lymphocyte count $<1.5 \times 10^{9} /$ I and monocyte count $>0.80 \times 10^{9} / \mathrm{I}$ NPS

Neutrophil count $\leq 7.5 \times 10^{9} / \mathrm{I}$ and platelet count $<400 \times 10^{9} / \mathrm{I}$

Neutrophil count $>7.5 \times 10^{9} / \mathrm{I}$ and platelet count $<400 \times 10^{9} / \mathrm{I}$

Neutrophil count $\leq 7.5 \times 10^{9} / \mathrm{l}$ and platelet count $>400 \times 10^{9} / \mathrm{l}$

Neutrophil count $>7.5 \times 10^{9} / \mathrm{I}$ and platelet count $>400 \times 10^{9} / \mathrm{I}$

CAR

C-reactive protein: albumin

C-reactive protein: albumin

mGPS

C-reactive protein $\leq 10 \mathrm{mg} / \mathrm{l}$ and albumin $\geq 35 \mathrm{~g} / \mathrm{l}$

C-reactive protein $>10 \mathrm{mg} / \mathrm{l}$ and albumin $\geq 35 \mathrm{~g} / \mathrm{l} \mathrm{I}$

C-reactive protein $>10 \mathrm{mg} / \mathrm{l}$ and albumin $<35 \mathrm{~g} / \mathrm{ll}$

$N L R$ neutrophil-lymphocyte ratio, NLS neutrophil-lymphocyte score, CAR Creactive protein albumin ratio, $M G P S$ modified Glasgow prognostic score, NPS neutrophil-platelet score, LMS lymphocyte-monocyte score, $L M R$ lymphocyte-monocyte ratio, PLR platelet-lymphocyte ratio, PLS platelet-lymphocyte score

C-reactive protein and albumin (Table 1). ${ }^{2,3}$ Also, recently the neutrophil-platelet score (NPS) using neutrophils and platelets has been reported. ${ }^{4}$ Clearly, the cumulative score approach can also be applied to the ratios described above (Table 1), such as NLR (termed neutrophil-lymphocyte score (NLS)), PLR (termed platelet-lymphocyte score (PLS)) and LMR (termed lymphocyte-monocyte score (LMS)).

Therefore, the aim of the present study was to compare the prognostic value of systemic inflammatory markers, in particular that of composite ratios and cumulative scores, in patients undergoing surgery for colon cancer.

\section{PATIENTS AND METHODS}

Patients were identified from a prospectively collected and maintained database of colon cancer resections undertaken in a single surgical unit at the Glasgow Royal Infirmary. Consecutive
Table 2a. The clinicopathological characteristics of patients undergoing surgery for colon cancer $(n=801)$

\begin{tabular}{|c|c|}
\hline Variables & $n=801(\%)$ \\
\hline \multicolumn{2}{|l|}{ Age (years) } \\
\hline$<65$ & $248(31)$ \\
\hline $65-74$ & $270(34)$ \\
\hline$>75$ & $283(35)$ \\
\hline \multicolumn{2}{|l|}{ Sex } \\
\hline Female & $371(46)$ \\
\hline Male & $430(54)$ \\
\hline \multicolumn{2}{|l|}{$\mathrm{BMI}^{\mathrm{a}}$} \\
\hline Underweight & $72(12)$ \\
\hline Normal & $190(31)$ \\
\hline Overweight & $192(32)$ \\
\hline Obese & $153(25)$ \\
\hline \multicolumn{2}{|l|}{ ASA grade $^{b}$} \\
\hline 1 & $97(17)$ \\
\hline 2 & $243(42)$ \\
\hline 3 & $208(36)$ \\
\hline 4 & $29(5)$ \\
\hline \multicolumn{2}{|l|}{ Presentation } \\
\hline Elective & $689(86)$ \\
\hline Emergency & $112(14)$ \\
\hline \multicolumn{2}{|l|}{ Type of surgery } \\
\hline Open & $679(85)$ \\
\hline Laparoscopic & $122(15)$ \\
\hline \multicolumn{2}{|c|}{ Neoadjuvant therapy ${ }^{c}$} \\
\hline No & $782(99)$ \\
\hline Yes & $8(1)$ \\
\hline \multicolumn{2}{|c|}{ Adjuvant therapy ${ }^{d}$} \\
\hline No & $574(75)$ \\
\hline Yes & $194(25)$ \\
\hline \multicolumn{2}{|l|}{ T stage } \\
\hline 1 & $52(6)$ \\
\hline 2 & $76(10)$ \\
\hline 3 & $418(52)$ \\
\hline 4 & $255(32)$ \\
\hline \multicolumn{2}{|l|}{$\mathrm{N}$ stage } \\
\hline 0 & $507(63)$ \\
\hline 1 & $207(26)$ \\
\hline 2 & $87(11)$ \\
\hline \multicolumn{2}{|l|}{ TNM stage } \\
\hline 1 & $116(14)$ \\
\hline 2 & $391(49)$ \\
\hline 3 & $294(37)$ \\
\hline \multicolumn{2}{|l|}{ Differentiation ${ }^{\mathrm{e}}$} \\
\hline Mod/well & $709(89)$ \\
\hline Poor & $86(11)$ \\
\hline \multicolumn{2}{|c|}{ Venous invasion ${ }^{f}$} \\
\hline No & $383(48)$ \\
\hline Yes & $416(52)$ \\
\hline \multicolumn{2}{|c|}{ Margin involvement ${ }^{f}$} \\
\hline No & $757(95)$ \\
\hline Yes & $42(5)$ \\
\hline \multicolumn{2}{|c|}{ Peritoneal involvement ${ }^{f}$} \\
\hline No & $578(72)$ \\
\hline Yes & $221(28)$ \\
\hline \multicolumn{2}{|c|}{ Tumour perforation ${ }^{f}$} \\
\hline No & $772(97)$ \\
\hline Yes & $27(3)$ \\
\hline
\end{tabular}

${ }^{a} n=607 .{ }^{b} n=575 .{ }^{c} n=790 .{ }^{d} n=778 .{ }^{e} n=795 .{ }^{f} n=799 . ~ B M I$ body mass index, ASA American Society of Anaesthesiologists, TNM tumour node metastasis 
Table $\mathbf{2 b}$. The correlation between composite ratios and cumulative scores and clinicopathological characteristics of patients undergoing elective surgery for colon cancer $(n=689)$

\begin{tabular}{|c|c|c|c|c|c|c|c|c|c|c|c|c|}
\hline & Age & Sex & BMI & $\begin{array}{l}\text { ASA } \\
\text { grade }\end{array}$ & T stage & $\mathrm{N}$ stage & Differentiation & $\begin{array}{l}\text { Venous } \\
\text { invasion }\end{array}$ & $\begin{array}{l}\text { Margin } \\
\text { involvement }\end{array}$ & $\begin{array}{l}\text { Peritoneal } \\
\text { involvement }\end{array}$ & $\begin{array}{l}\text { Tumour } \\
\text { perforation }\end{array}$ & $\begin{array}{l}\text { Adjuvant } \\
\text { therapy }\end{array}$ \\
\hline NLR & 0.009 & 0.398 & $<0.001$ & 0.156 & 0.069 & 0.287 & 0.018 & 0.002 & 0.219 & 0.195 & $<0.001$ & 0.063 \\
\hline PLR & $<0.001$ & 0.391 & $<0.001$ & 0.294 & 0.001 & 0.395 & 0.087 & 0.214 & 0.095 & 0.002 & 0.803 & 0.758 \\
\hline PLS & 0.008 & 0.827 & $<0.001$ & 0.337 & 0.001 & 0.449 & 0.029 & 0.002 & 0.012 & 0.005 & 0.043 & 0.907 \\
\hline LMR & $<0.001$ & 0.004 & 0.030 & 0.705 & 0.063 & 0.948 & 0.557 & 0.133 & 0.750 & 0.085 & 0.041 & 0.067 \\
\hline NPS & 0.649 & 0.990 & 0.016 & 0.753 & 0.004 & 0.017 & 0.005 & 0.013 & 0.015 & 0.277 & 0.375 & 0.341 \\
\hline CAR & 0.008 & 0.618 & 0.027 & 0.009 & $<0.001$ & 0.071 & 0.001 & 0.011 & 0.037 & 0.007 & 0.004 & 0.341 \\
\hline mGPS & 0.180 & 0.913 & $<0.001$ & 0.294 & $<0.001$ & 0.616 & $<0.001$ & 0.006 & 0.005 & 0.003 & 0.001 & 0.422 \\
\hline
\end{tabular}

patients who met the following criteria were included: first, those who had preoperative measurement of serum CRP, albumin and differential blood cell counts within 30 days before surgery; second, those who, on the basis of preoperative abdominal computed tomography and laparotomy findings, were considered to have undergone potentially curative resection for colonic cancer between January 1997 and June 2014. Patients with inflammatory bowel disease-related cancer, who underwent resection with palliative intent or local resection only, or had not had preoperative measurement of CRP or albumin, were excluded. ${ }^{5}$ Tumours were staged using the fifth edition of the tumour node metastasis (TNM) classification, with additional data taken from pathological reports issued after resection. ${ }^{6}$ After surgery, all patients were discussed at a multidisciplinary meeting involving surgeons, oncologists, radiologists and pathologists with special interest in colorectal cancer; patients with stage III or highrisk stage II disease and no significant comorbidities precluding chemotherapy use were offered primarily 5-fluorouracil-based adjuvant chemotherapy on the basis of current guidelines at the time.

Preoperative serum CRP, albumin and differential blood cell counts were recorded prospectively. NLR, PLR, LMR and CAR were all calculated by directly dividing the former by the latter (Table 1). The NLS, PLS, LMS, NPS and mGPS were all constructed using normal reference ranges (Table 1).

Patients were routinely followed up for 5 years after surgery. Date and cause of death were crosschecked with the cancer registration system and the Registrar General (Scotland). Death records were complete until 30 June 2017, which acted as the censor date. Cancer-specific survival (CSS) was measured from the date of surgery until the date of death from recurrent or metastatic colonic cancer. Overall survival (OS) was measured until the date of death from any cause. The West of Scotland Research Ethics Committee approved the study.

\section{Statistics}

The cut-off values for individual ratios were examined using receiver operating characteristic (ROC) curve analyses. The threshold values of such characteristics were based on the most prominent point on the ROC curve for 'sensitivity' and '1specificity', respectively. The optimal threshold values were defined using the Youden index (maximum (sensitivity + specificity -1)) and these were compared with published validated values to determine the value used in the subsequent analysis. ${ }^{7,8}$
The area under the ROC curve also was calculated. The relationship between NLR, PLR, LMR, CAR, NLS, PLS, LMS and mGPS and both CSS and OS was assessed using Cox proportional hazards regression to calculate hazard ratios (HRs) and 95\% confidence intervals $(95 \% \mathrm{Cls})$. The relationship between NLR, PLR, LMR, CAR, NLS, PLS, LMS and mGPS and patient clinicopathological characteristics was assessed using Pearson's $X^{2}$ tests. In order to adjust for multiple comparisons during the correlation of composite ratios and cumulative scores and clinicopathological characteristics a $p$ value of $<0.01$ was considered significant. All analyses were performed using SPSS version 22.0 (IBM Corp, Armonk, NY, USA).

\section{RESULTS}

From the prospectively maintained database, 801 patients undergoing potentially curative resection for colon cancer were examined (Table 2a). The majority of patients were over 65 years of age $(69 \%)$, were male $(54 \%)$, were overweight or obese $(57 \%)$ and were American Society of Anaesthesiologists' grade 2 or greater (83\%). The majority of patients presented electively (86\%), had an open resection (85\%) and did not receive adjuvant therapy (75\%). The majority of patients had either TNM stage II or III disease $(86 \%)$ with moderate/well- differentiated tumours $(n=$ $703,89 \%)$ and venous invasion (52\%). The majority of patients had no margin involvement (95\%), peritoneal involvement $(72 \%)$ or tumour perforation (97\%) at the time of resection. On follow-up there were 237 (28\%) cancer-related deaths and 437 (52\%) deaths overall.

The relationship between the composite ratios and cumulative scores and the clinicopathological characteristics of patients undergoing elective surgery for colon cancer is shown in Table $2 \mathrm{~b} \quad(n=689)$. There was statistically significant correlation between the majority of the composite ratios and cumulative scores and age $(p<0.01), \mathrm{BMI}(p<0.01)$, T stage $(p<0.01)$, venous invasion $(p<0.01)$ and peritoneal involvement $(p<0.01)$.

The relationship between composite ratios and cumulative scores and their component values in patients undergoing surgery for colon cancer is shown in Table $2 c(n=801)$. The majority were not assigned as systemically inflamed prior to surgery according to either ratios or scores (NLR $>5-19 \%$, NLS $>0-47 \%$, PLR $>150$ $-65 \%$, PLS $>0-48 \%$, NPS $>0-28 \%$, CAR $>0.22-49 \%$, mGPS $>0$ $-41 \%)$. 
Table 2c. The relationship between composite ratios and cumulative scores and their component values in patients undergoing surgery for colon cancer $(n=801)$

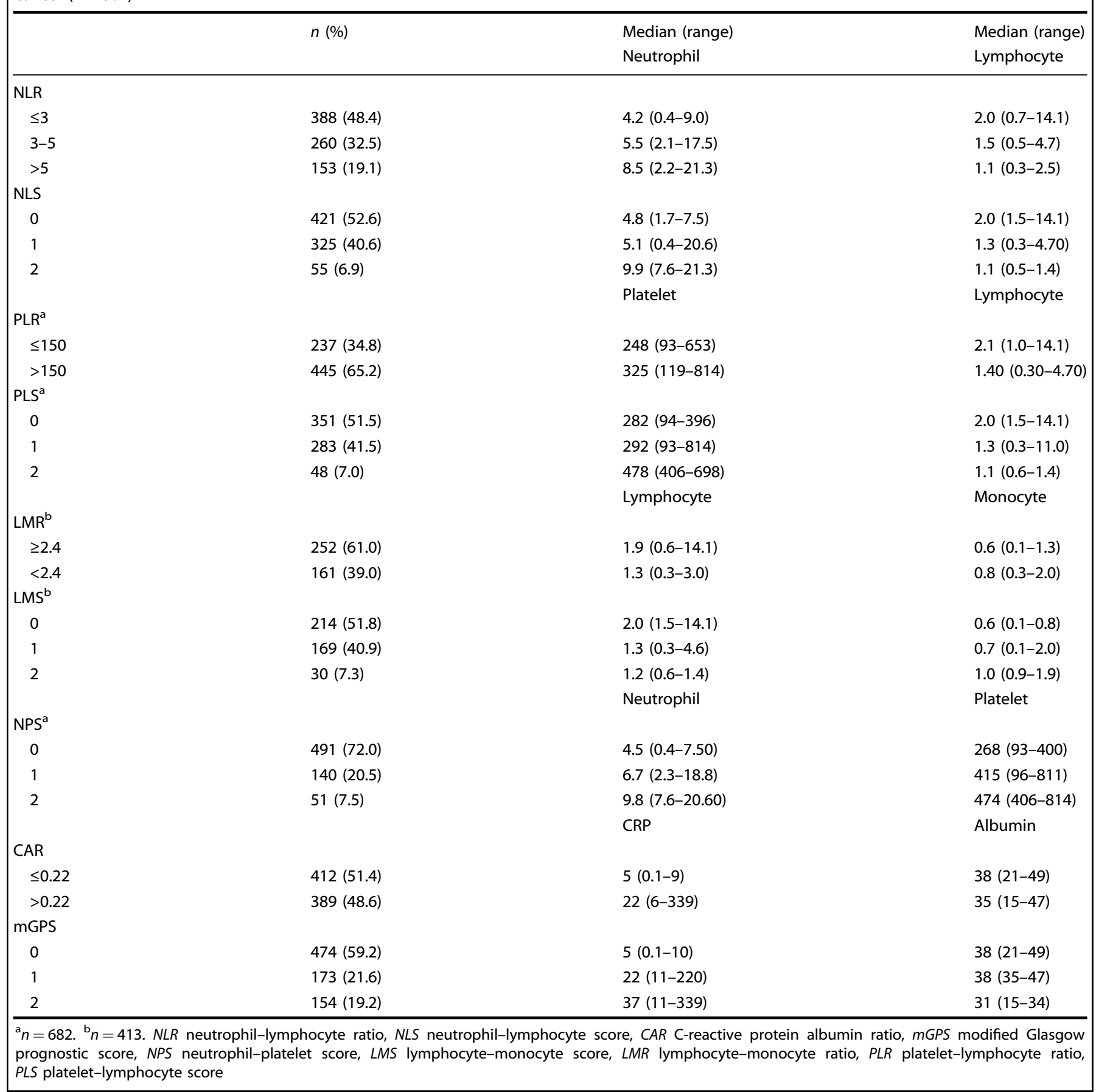

The median values for the components of the ratios and scores are shown in Table 2c. An NLR 3-5 was associated with a median neutrophil count of $5.5 \times 10^{9} / \mathrm{I}$ and a median lymphocyte count of $1.5 \times 10^{9} /$, both within the normal reference range. In contrast, an NLR $>5$ was associated with a median neutrophil count of $8.5 \times$ $10^{9} / /$ and a median lymphocyte count of $1.1 \times 10^{9} / \mathrm{l}$, both outside the normal reference range. A PLR $>150$ was associated with a median platelet count of $325 \times 10^{9} / \mathrm{l}$ and a median lymphocyte count of $1.4 \times 10^{9} / \mathrm{l}$, the platelet count being within the normal reference range. An LMR $<2.4$ was associated with a median lymphocyte count of $1.3 \times 10^{9} / \mathrm{l}$ and a median monocyte count of $0.8 \times 10^{9} /$, monocyte count being within the normal reference range. A CAR $>0.22$ was associated with a median CRP concentration of $24 \mathrm{mg} / \mathrm{l}$ and a median albumin concentration of $36 \mathrm{~g} / \mathrm{l}$, with albumin being within the normal reference range.

The relationship between validated ratios, scores and 5-year CSS in patients undergoing surgery for colon cancer is shown in Table 3 and Figs. 1-4. On ROC analysis using standard thresholds and CSS as an end-point, the AUC for TNM stage was 0.649, NLR 


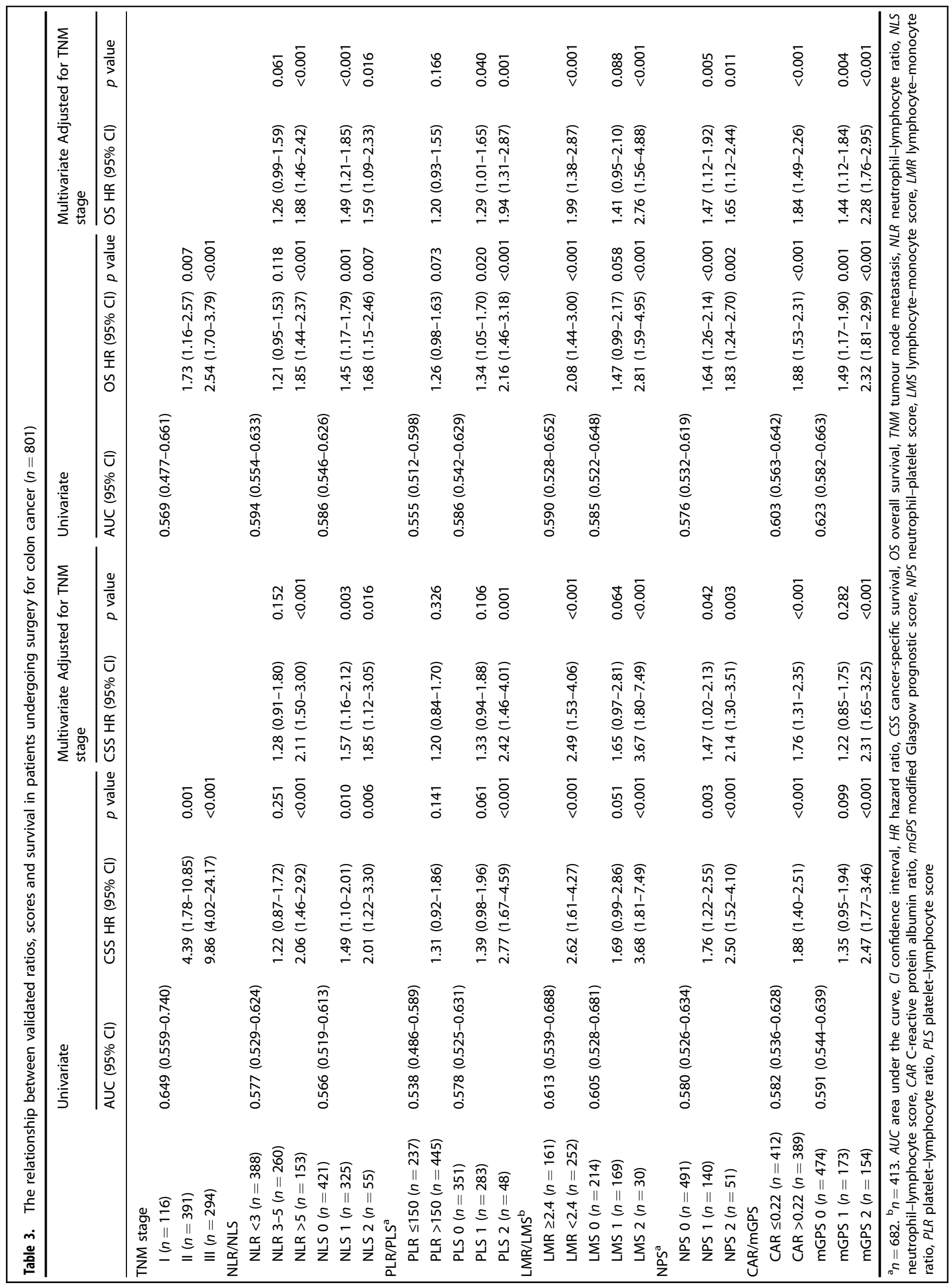


a

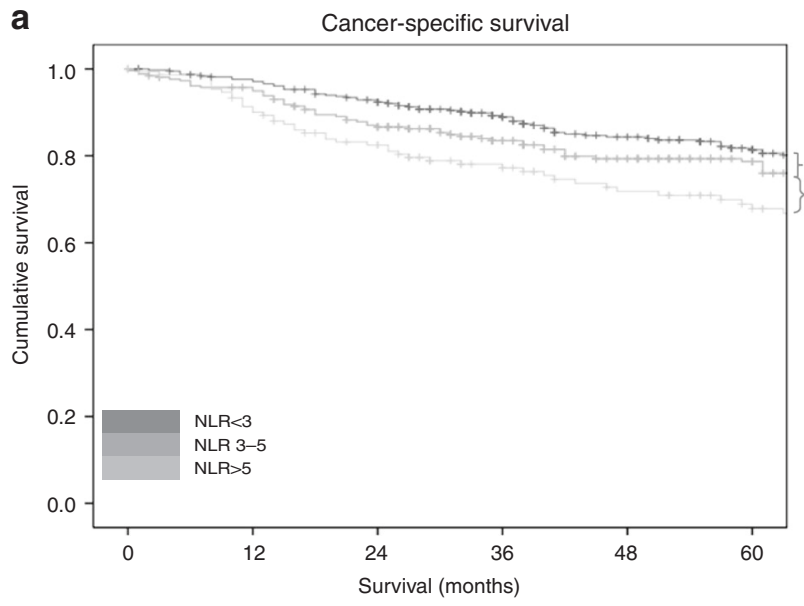

\begin{tabular}{|l|l|l|l|l|l|l|}
\hline $\begin{array}{l}\text { Number } \\
\text { at risk }\end{array}$ & 0 & 12 & 24 & 36 & 48 & 60 \\
\hline NLR $<3$ & 388 & 377 & 395 & 374 & 333 & 325 \\
\hline NLR 3-5 & 206 & 274 & 226 & 291 & 211 & 210 \\
\hline NLR $>5$ & 153 & 138 & 127 & 120 & 114 & 110 \\
\hline
\end{tabular}

c

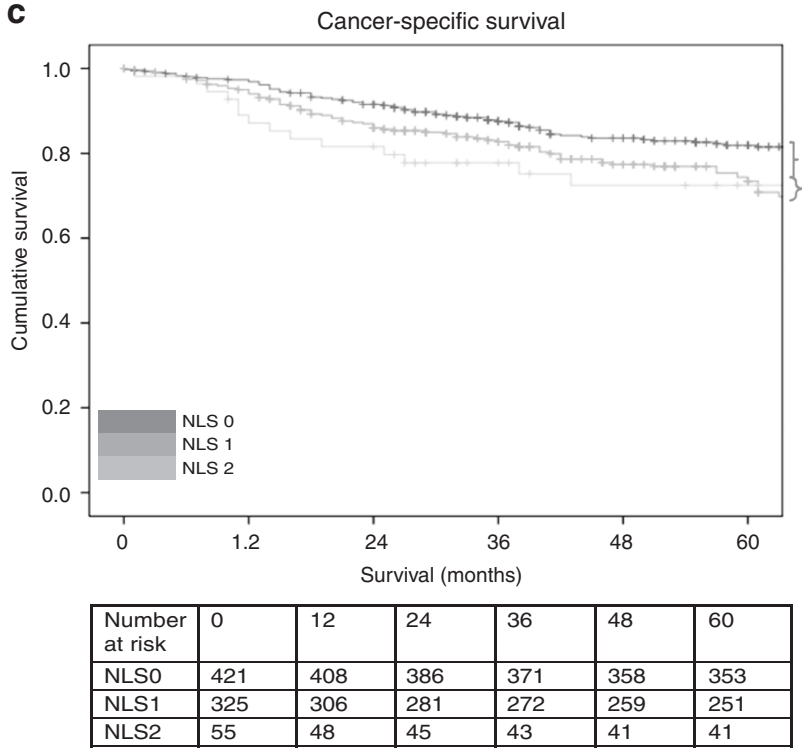

b

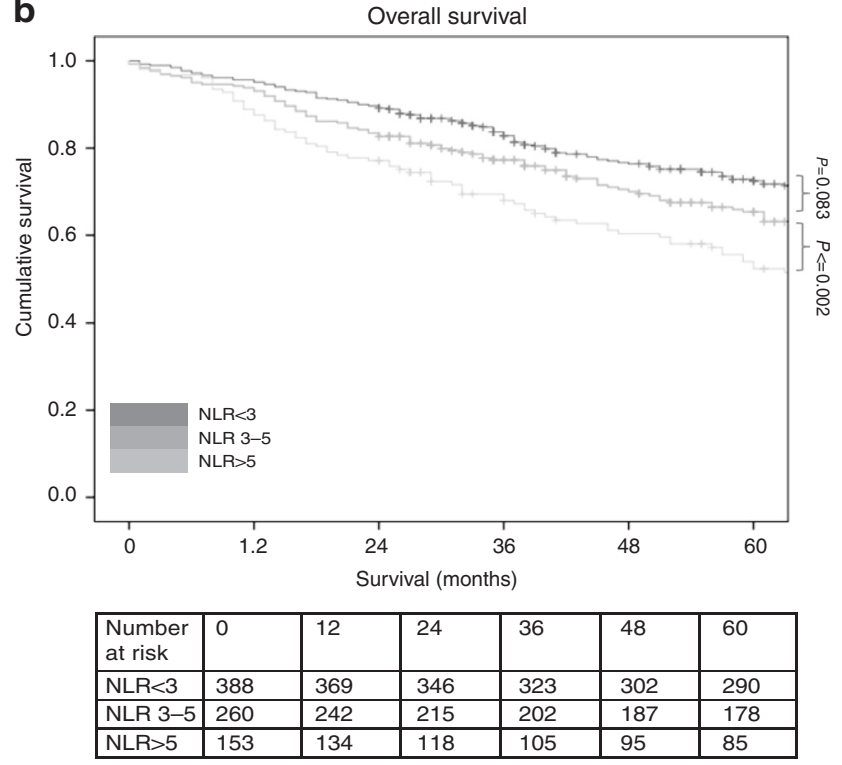

d

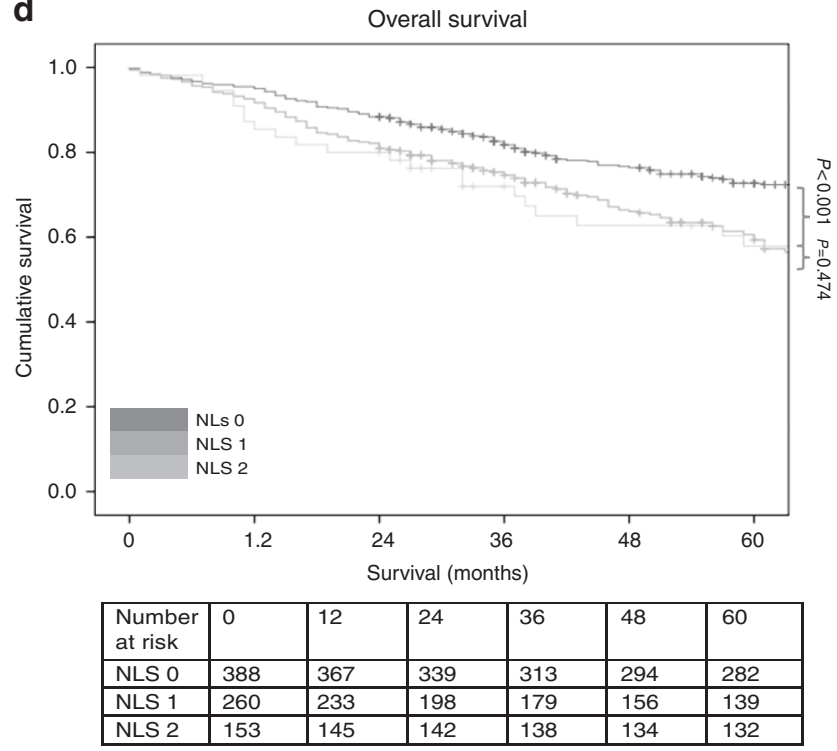

Fig. 1 a-d The relationship between the NLR and NLS and both CSS and OS in patients undergoing surgery for colon cancer. Number at risk depicts the number of patients alive or not censored entering each time period

was 0.577 , NLS was 0.566 , PLR was 0.538 , PLS was 0.607 , LMR was 0.613 , LMS was 0.605 , NPS was 0.580 , CAR was 0.582 and $\mathrm{mGPS}$ was 0.591 . When adjusted for TNM stage, NLR $>5(p<0.001)$, NLS 1 and 2 (both $p \leq 0.01), \operatorname{PLS} 2(p<0.001), \operatorname{LMR}<2.4(p<0.001)$, LMS 2 $(p<0.001)$, NPS $2(p \leq 0.001)$, CAR $>0.22(p<0.001)$, mGPS $2(p<$ $0.001)$ were significantly associated with CSS.

On ROC analysis using standard thresholds and 5-year OS as an end-point, the following AUC for TNM stage was 0.569, NLR was 0.594 , NLS was 0.586 , PLR was 0.555 , PLS was 0.620 , LMR was 0.590 , LMS was 0.585 , NPS was 0.576 , CAR was 0.603 and mGPS was 0.623 . When adjusted for TNM stage, NLR $>5(p<0.001)$, NLS 1 and 2 (both $p \leq 0.01)$, PLS $2(p<0.001)$, LMR $<2.4(p<0.001)$, LMS 2 $(p<0.001)$, NPS $2(p \leq 0.01)$, CAR $>0.22(p<0.001), \operatorname{mGPS} 2(p<$ 0.001 ) were all significantly associated with overall survival (Table 3 and Figs. 1-4).
The complementary prognostic value of the cumulative scores NPS and mGPS, markers of innate immune activation from two different organs, were examined in the context of TNM staging (Table 4). Within TNM stage II disease the 5 -year CSS rate was $82 \%$ and the 5 -year CSS rate varied between 86 and $73 \%$ according to the NPS and between 86 and $79 \%$ according to the mGPS. The 5year OS rate was $57 \%$ and the 5 -year OS rate varied between 61 and $47 \%$ according to the NPS and between 65 and $48 \%$ according to the mGPS.

Within TNM stage III disease, the 5-year CSS rate was $65 \%$ and the 5-year CSS rate varied between 67 and $60 \%$ according to the NPS and between 69 and 59\% according to the mGPS. The 5-year OS rate was $47 \%$ and the 5 -year OS varied between 51 and $37 \%$ according to the NPS and between 53 and $38 \%$ according to the mGPS (Table 4). 
a

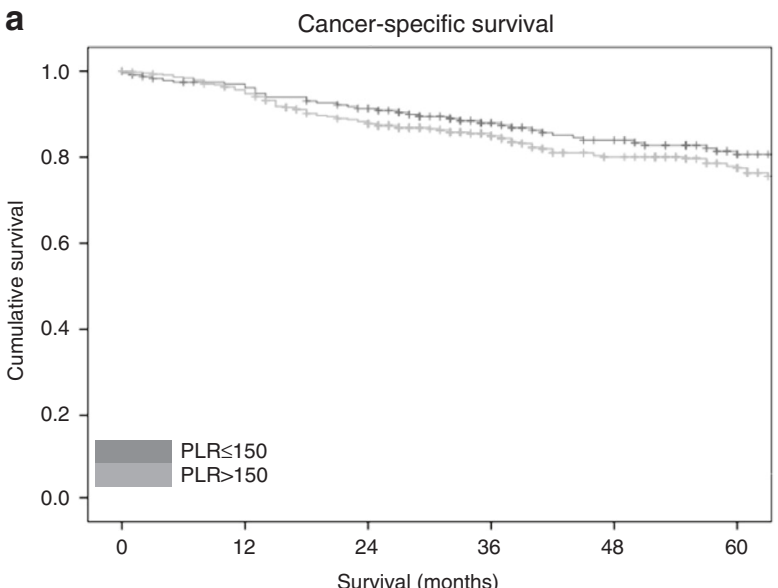

\begin{tabular}{|l|l|l|l|l|l|l|}
\hline $\begin{array}{l}\text { Number } \\
\text { at risk }\end{array}$ & 0 & 12 & 24 & 36 & 48 & 60 \\
\hline PLR $\leq 150$ & 237 & 228 & 217 & 210 & 203 & 198 \\
\hline PLR $>150$ & 445 & 422 & 392 & 381 & 365 & 358 \\
\hline
\end{tabular}

C

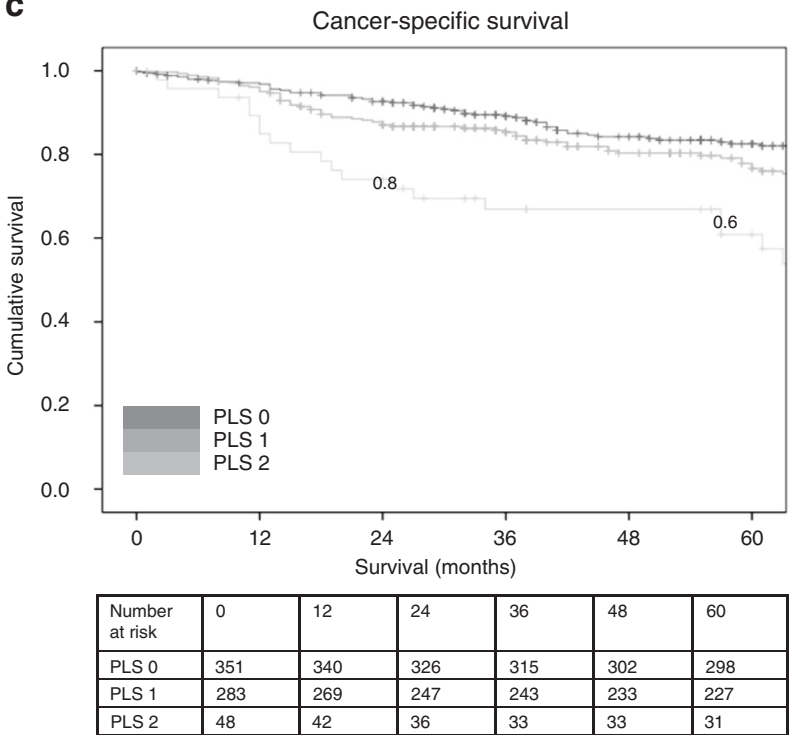

b

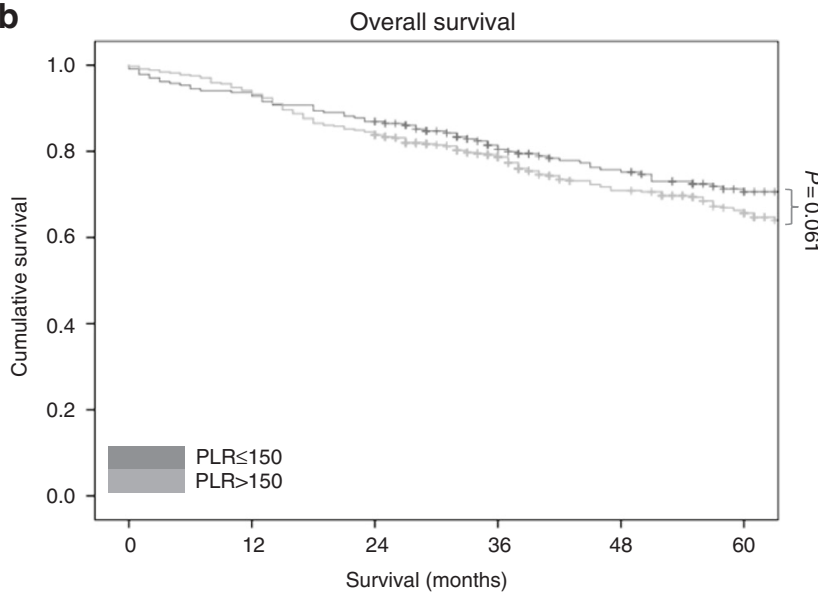

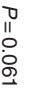

\begin{tabular}{|l|l|l|l|l|l|l|}
\hline $\begin{array}{l}\text { Number } \\
\text { at risk }\end{array}$ & 0 & 12 & 24 & 36 & 48 & 60 \\
\hline PLR $\leq 150$ & 237 & 220 & 206 & 192 & 182 & 174 \\
\hline PLR $>150$ & 445 & 415 & 373 & 352 & 324 & 307 \\
\hline
\end{tabular}

d

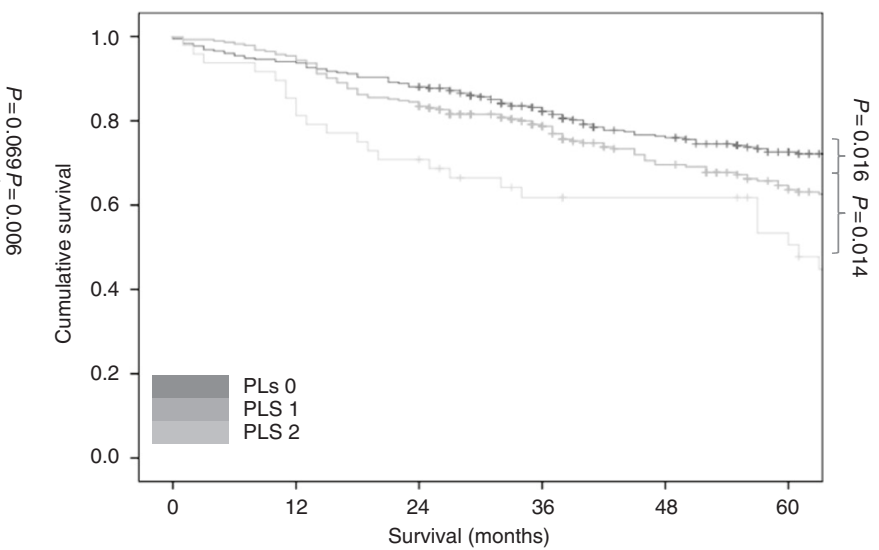

\begin{tabular}{|l|l|l|l|l|l|l|}
\hline $\begin{array}{l}\text { Number } \\
\text { at risk }\end{array}$ & 0 & 12 & 24 & 36 & 48 & 60 \\
\hline PLS 0 & 351 & 329 & 309 & 290 & 272 & 263 \\
\hline PLS 1 & 283 & 267 & 236 & 224 & 204 & 192 \\
\hline PLS 2 & 48 & 39 & 34 & 30 & 30 & 26 \\
\hline
\end{tabular}

Fig. 2 a-d The relationship between the PLR and PLS and both CSS and OS in patients undergoing surgery for colon cancer. Number at risk depicts the number of patients alive or not censored entering each time period

\section{DISCUSSION}

The results of the present study directly compare, for the first time, the prognostic value of composite ratios and cumulative scores of the systemic inflammatory response. These ratios and scores, whether composed of white cells from lymphoid/myeloid tissue or from acute phase proteins from the liver, had prognostic value, independent of TNM stage, in patients with colon cancer. Moreover, systemic inflammation scores from different organs had similar prognostic value. Taken together, the systemic inflammatory response represents an important prognostic domain to be monitored in patients with colon cancer.

In the present study, it was of interest that the ratio thresholds did not always differentiate normal from abnormal values of the composite values. The discrepancy between the ratio threshold and the abnormal single component is shown in Fig. 5a-e. In Fig. $5 a$, using the line of best fit, an NLR $>5$ was associated with a median neutrophil count of approximately 7.5, at the top of the normal reference range. In contrast, a NLR $>3$ was associated with a neutrophil count of approximately 4.5 , within in the normal reference range. With reference to PLR $>150$, it was associated with a platelet count of approximately 200, within the normal range (Fig. $5 b$ ). With reference to $L M R<2.4$, it was associated with a lymphocyte count of 1.5 , at the bottom of the normal range (Fig. 5 C). Finally, with reference to CAR $>0.22$ was associated with a CRP of 10 well above the normal range (Fig. $5 \mathrm{~d}$ ). Therefore, it is clear that a number of ratios (e.g. NLR $>3$ and PLR $>150$ ) do not describe components with abnormal values. Moreover, the ratios, compared with scores, consistently assigned a higher proportion of patients to be systemically inflamed. Given that scores based on abnormal value are simpler to construct and have similar and overlapping prognostic value, independent of TNM stage, compared with composite ratios (Table 3 ), the rationale for the continued use of such ratios is problematic. Indeed, recent clinical 
a

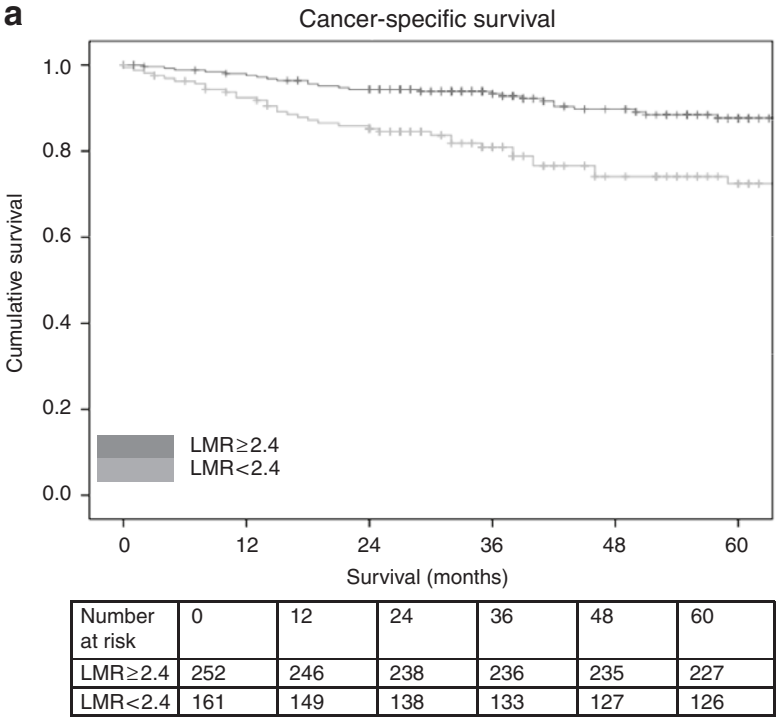

C

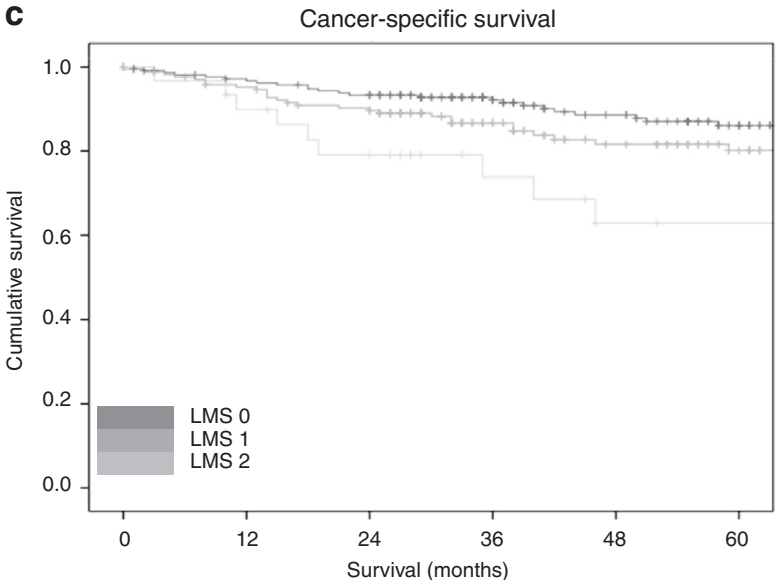

\begin{tabular}{|l|l|l|l|l|l|l|}
\hline $\begin{array}{l}\text { Number } \\
\text { at risk }\end{array}$ & 0 & 12 & 24 & 36 & 48 & 60 \\
\hline LMS 0 & 214 & 207 & 200 & 198 & 193 & 190 \\
\hline LMS 1 & 169 & 161 & 152 & 148 & 143 & 142 \\
\hline LMS 2 & 30 & 27 & 24 & 23 & 21 & 21 \\
\hline
\end{tabular}

b

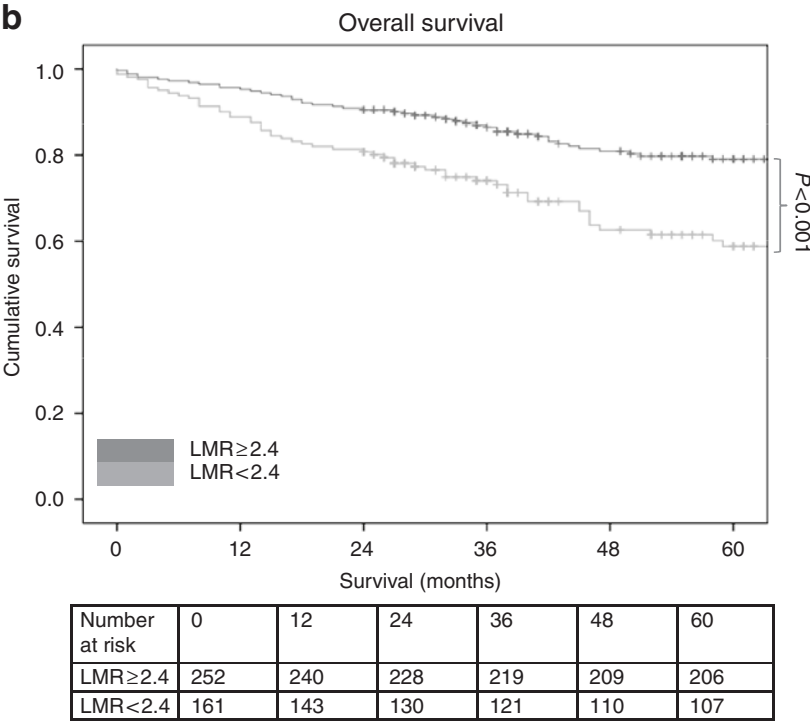

d

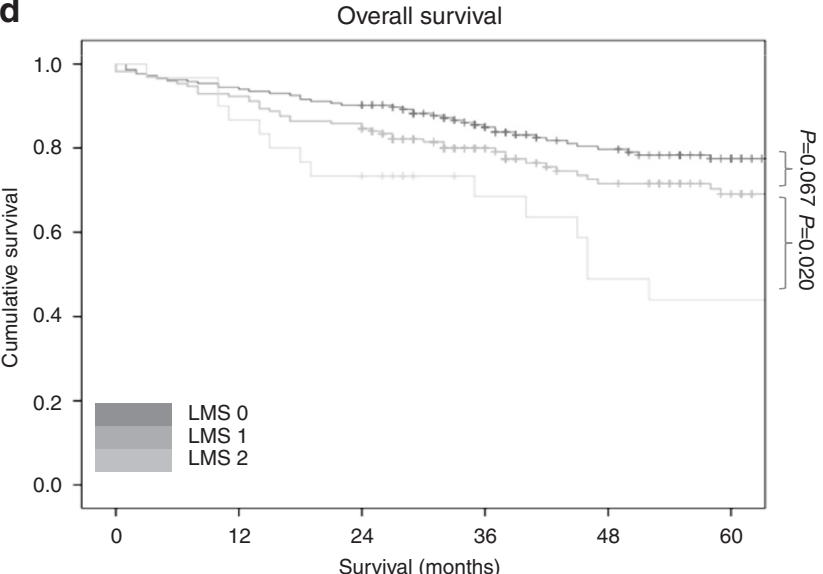

\begin{tabular}{|l|l|l|l|l|l|l|}
\hline $\begin{array}{l}\text { Number } \\
\text { at risk }\end{array}$ & 0 & 12 & 24 & 36 & 48 & 0 \\
\hline LMS 0 & 214 & 201 & 193 & 183 & 175 & 172 \\
\hline LMS 1 & 169 & 156 & 143 & 136 & 127 & 125 \\
\hline LMS 2 & 30 & 26 & 22 & 21 & 1 & 16 \\
\hline
\end{tabular}

Fig. 3 a-d The relationship between the LMR and LMS and both CSS and OS in patients undergoing surgery for colon cancer. Number at risk depicts the number of patients alive or not censored entering each time period

calculators for survival in patients with metastatic colorectal cancer, based on data of more than 20,000 patients from randomised controlled trials (ARCAD database), has incorporated the white cell count, neutrophil count, platelet count and albumin level as scores rather than derived ratios. ${ }^{9,10}$ Furthermore Dupré and Malik ${ }^{11}$ have argued that the variability of reported prognostic thresholds of NLR, PLR and LMR questions their reliability for routine clinical practice.

Although it is presumed that composite ratios of lymphoid/ myeloid cells and acute phase proteins reflect similar aspects of the systemic inflammatory response, it is clear from the plot of NLR and CAR (Fig. 5e) that these ratios do not simply mirror one another. In contrast, when cumulative scores such as NPS and mGPS, based on normal reference ranges, were compared there was better agreement in terms of systemic inflammatory response status and prognostic value (Table 4). However, it should be noted that although C-reactive protein and albumin are similar proteins components of a differential WCC such as neutrophil count are composed of a number of cell types. ${ }^{12}$ Irrespective the cumulative score approach, based on normal reference ranges, improves our understanding of aspects of the activation of the innate systemic inflammatory response. The simplicity and consistency of this approach has much to commend it.

The innate systemic inflammatory response in patients with cancer, as well as incorporating responses from lymphoid/myeloid tissue and the liver, incorporates responses from other organs and tissues. In particular, the response from the sympathetic nervous system is of interest since similar to that of NPS and mGPS, it is intimately connected with immune responses. ${ }^{13}$ Having established, in patients with cancer, the prognostic value of simple and objective markers of activation of lymphoid/myeloid and liver tissue activation, it would be of considerable interest to examine the prognostic value of objective markers of activation of the sympathetic nervous system.

In the present study, there was a clear correlation between higher composite ratios and cumulative scores and increased age, 
a

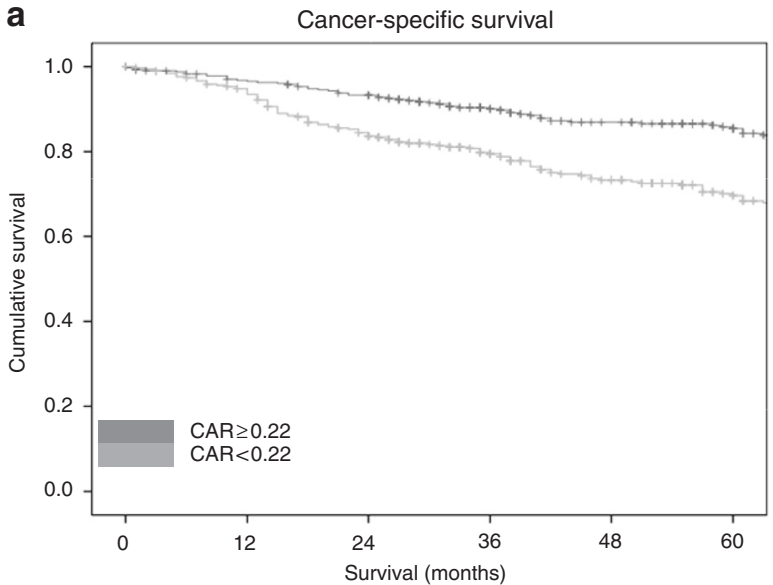

\begin{tabular}{|l|l|l|l|l|l|l|}
\hline $\begin{array}{l}\text { Number } \\
\text { at risk }\end{array}$ & 0 & 12 & 24 & 36 & 48 & 60 \\
\hline CAR $\geq 0.22$ & 412 & 398 & 385 & 373 & 363 & 359 \\
\hline CAR $<0.22$ & 389 & 364 & 327 & 313 & 295 & 286 \\
\hline
\end{tabular}

C

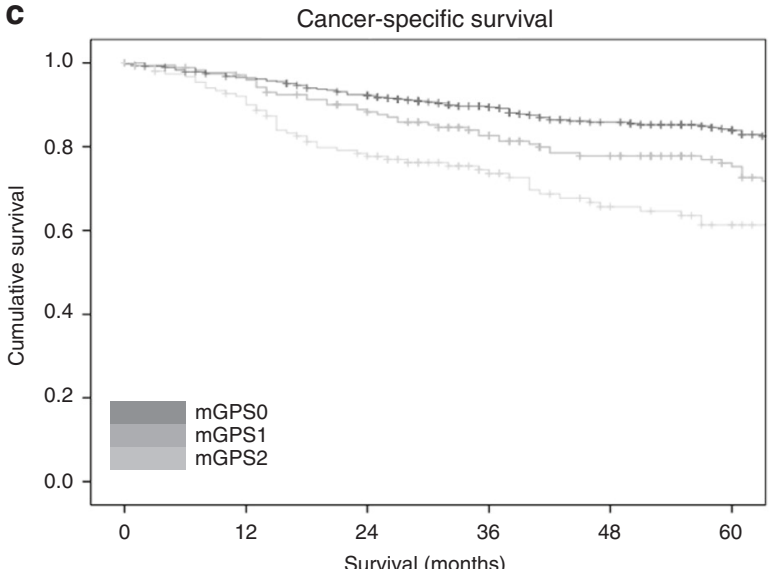

\begin{tabular}{|l|l|l|l|l|l|l|}
\hline $\begin{array}{l}\text { Number } \\
\text { at risk }\end{array}$ & 0 & 12 & 24 & 36 & 48 & 60 \\
\hline mGPS0 & 474 & 457 & 438 & 426 & 413 & 407 \\
\hline mGPS1 & 173 & 166 & 153 & 144 & 137 & 134 \\
\hline mGPS2 & 154 & 139 & 121 & 116 & 108 & 104 \\
\hline
\end{tabular}

b

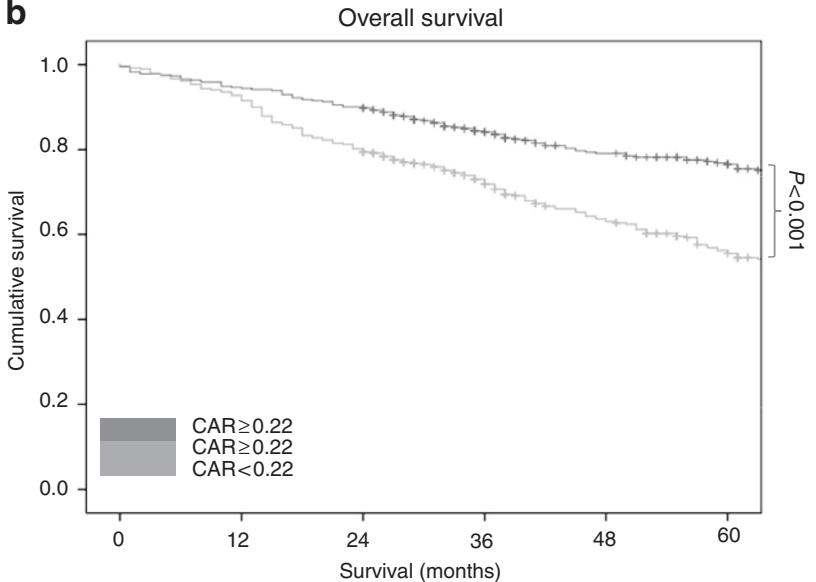

\begin{tabular}{|l|l|l|l|l|l|l|}
\hline $\begin{array}{l}\text { Number } \\
\text { at risk }\end{array}$ & 0 & 12 & 24 & 36 & 48 & 60 \\
\hline CAR $\geq 0.22$ & 41 & 400 & 370 & 348 & 331 & 323 \\
\hline CAR $<0.22$ & 389 & 356 & 309 & 282 & 254 & 230 \\
\hline
\end{tabular}

d

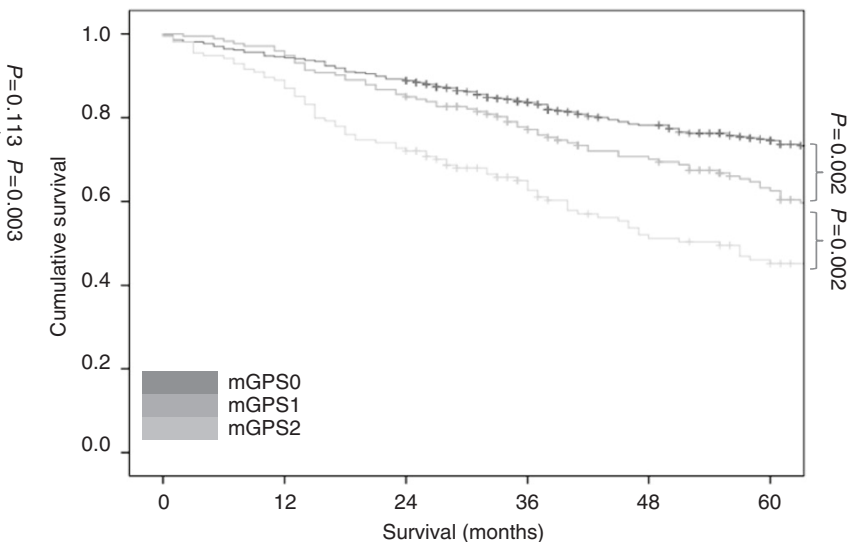

\begin{tabular}{|l|l|l|l|l|l|l|}
\hline $\begin{array}{l}\text { Number } \\
\text { at risk }\end{array}$ & 0 & 12 & 24 & 36 & 48 & 60 \\
\hline mGPS0 & 474 & 447 & 421 & 398 & 377 & 364 \\
\hline mGPS1 & 173 & 164 & 147 & 134 & 123 & 112 \\
\hline mGPS2 & 154 & 134 & 121 & 68 & 84 & 77 \\
\hline
\end{tabular}

Fig. 4 a-d The relationship between the CAR and mGPS and both CSS and OS in patients undergoing surgery for colon cancer. Number at risk depicts the number of patients alive or not censored entering each time period

$\mathrm{BMI}$, advanced $\mathrm{T}$ stage and the presence of both venous and peritoneal invasion. These clinicopathological characteristics are also directly associated with a poorer prognosis adding further weight to the prognostic ability of both composite ratios and cumulative score in patients with colonic cancer.

Recently, Park et al. $^{5}$ reported that the mGPS provides complimentary prognostic information to current TNM-based staging. When TNM staging and MGPS were combined, the 5year OS ranged from $92 \%$ (TNM 0, mGPS $=0$ ) to $26 \%$ (stage III, mGPS $=2$ ) and the 10-year OS ranged from 92\% (TNM 0, mGPS = $0)$ to $17 \%($ TNM III, mGPS $=2)(p<0.001)$. This further highlights the prognostic ability of the mGPS which is complementary to the gold standard of TNM staging with both being routinely available worldwide. ${ }^{5}$

The present study has a number of possible limitations. Although a relatively large prospective cohort, there were small numbers of observations in some sub-group analysis. Furthermore, data relating to other factors that may have affected markers of the systemic inflammatory response such drugs taken prior to sampling were not available. Although the present study used the 5th rather than the 7th edition of the TNM staging system, this was recommended in the 2014 Colorectal Cancer Care Guidelines of the Royal College of Pathologists and as such is the basis for all current UK wide practice. ${ }^{14}$ Furthermore, migration from the 5th to 7th edition would be expected to account for an upstaging from node-negative to node-positive disease in $<3 \%$ of cases, with little subsequent effect on prognosis. ${ }^{14-16}$

A maximum of a 30-day interval between laboratory testing and surgery may be considered to be too long. However, this timescale has been widely reported in the literature and consistent with the chronic nature of the standardised incidence ratio in patients with cancer. ${ }^{3}$ Also, patients with inflammatory bowel disease-related cancers were not included in the analysis. As such, the patient confounding factors of active systemic inflammatory disease and acute changes in the inflammatory state have been minimised. 


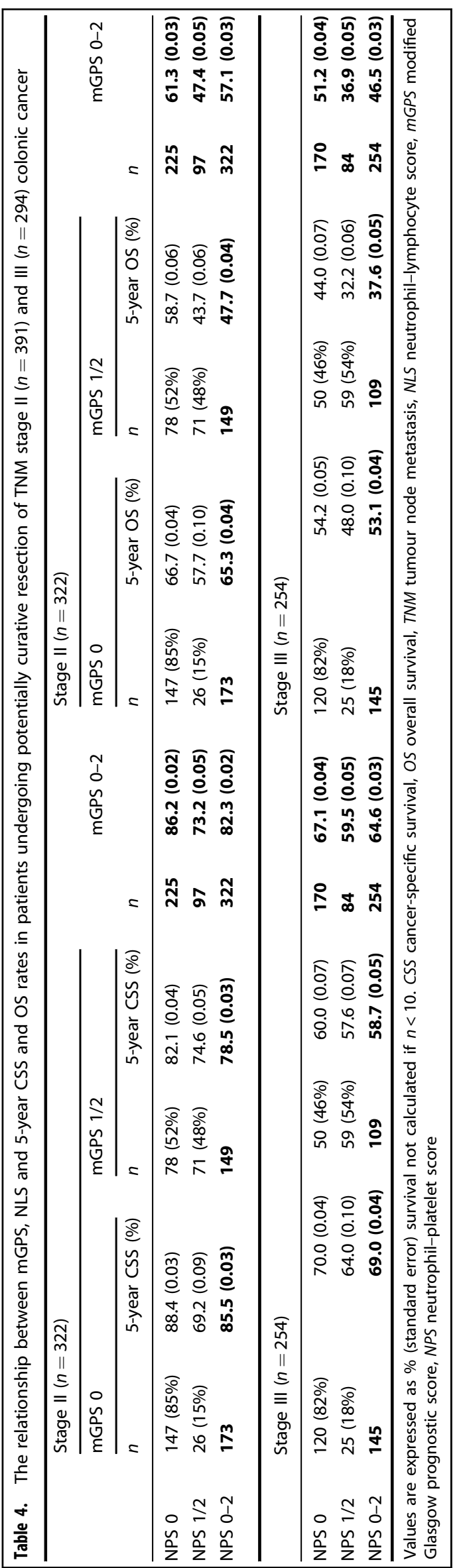


a

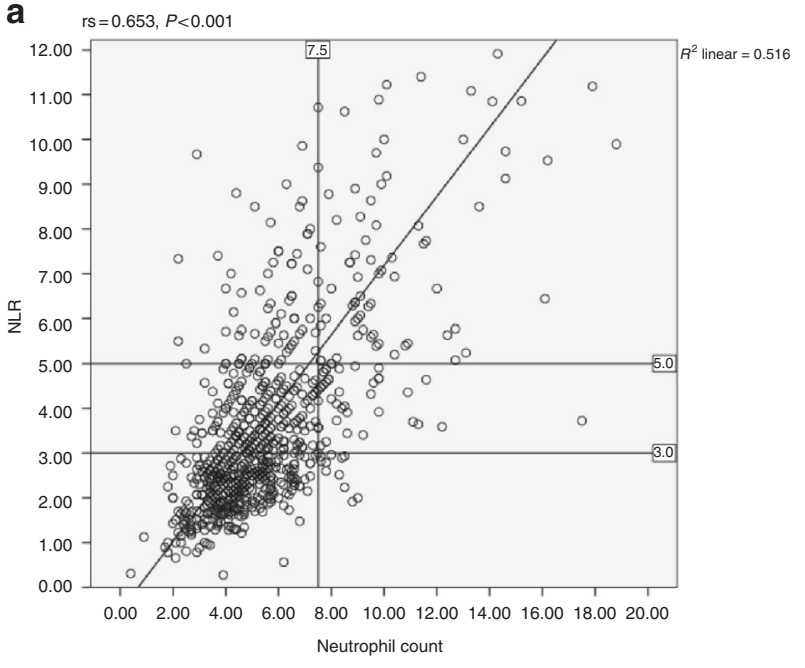

C

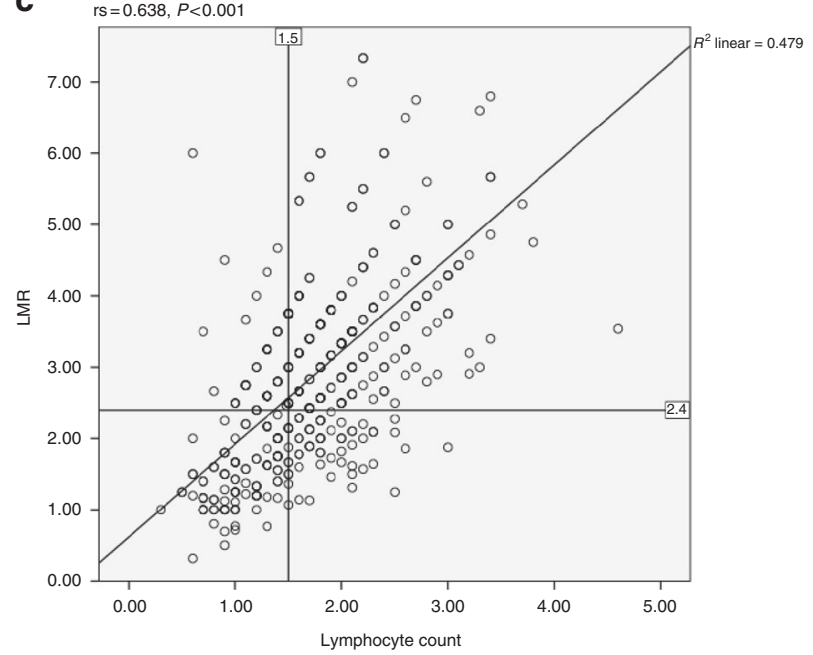

b

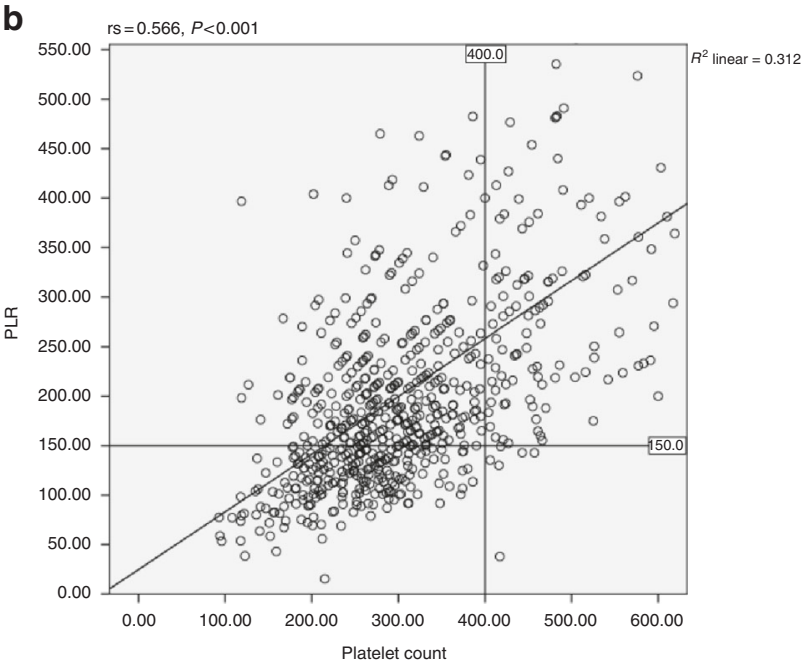

d

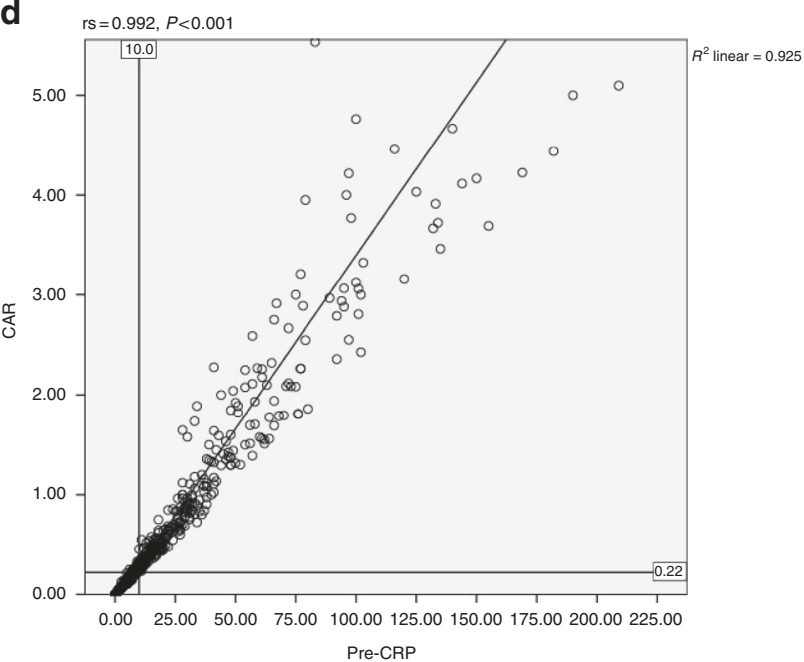

e $\quad \mathrm{rs}=0.329, P<0.001$

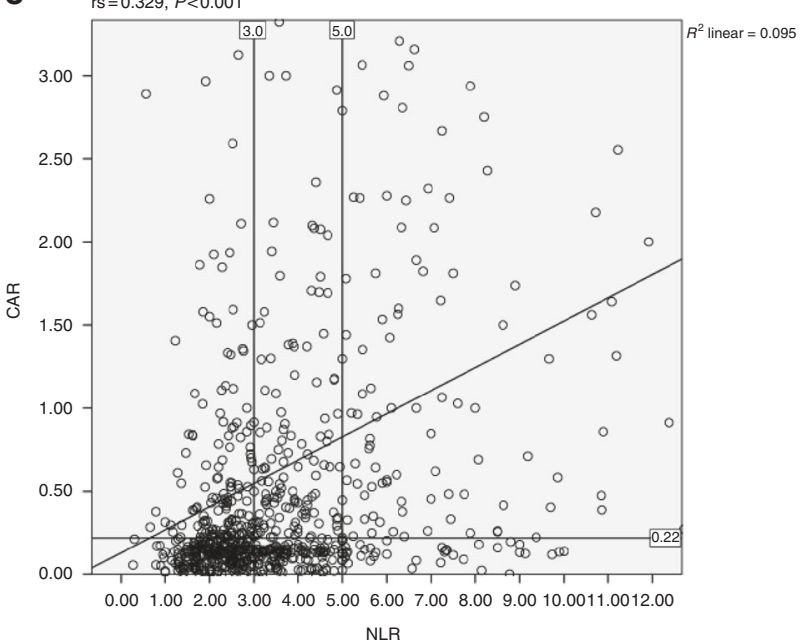

Fig. 5 a-e Plot of preoperative neutrophil count and NLR, platelet count and PLR, lymphocyte count and LMR, CRP and CAR, NLR and CAR in all patients undergoing surgical resection for colon cancer

In summary, present study directly compares, for the first time, the prognostic value of composite ratios and cumulative scores of the systemic inflammatory response. These ratios and scores, whether composed of white cells from lymphoid/myeloid tissue or from acute phase proteins from the liver, had prognostic value, independent of TNM stage, in patients with colon cancer. However, cumulative scores, based on normal reference ranges, are simpler and more consistent for clinical use. 


\section{ADDITIONAL INFORMATION}

Competing interests: The authors declare no competing interests.

Note: This work is published under the standard license to publish agreement. After 12 months the work will become freely available and the license terms will switch to a Creative Commons Attribution 4.0 International (CC BY 4.0).

\section{REFERENCES}

1. 2014 C. Cancer Research UK: Statistics and Outlook for Bowel Cancer UK: Cabc [Cancer Research UK statistics]. http://www.cancerresearchuk.org/about-cancer/ type/ (2014).

2. Dolan, R. D., McSorley, S. T., Horgan, P. G., Laird, B. \& McMillan, D. C. The role of the systemic inflammatory response in predicting outcomes in patients with advanced inoperable cancer: systematic review and meta-analysis. Crit. Rev. Oncol. Hematol. 116, 134-146 (2017).

3. Dolan, R. D., Lim, J., McSorley, S. T., Horgan, P. G. \& McMillan, D. C. The role of the systemic inflammatory response in predicting outcomes in patients with operable cancer: systematic review and meta-analysis. Sci. Rep. 7, 16717 (2017).

4. Watt, D. G., Proctor, M. J., Park, J. H., Horgan, P. G. \& McMillan, D. C. The neutrophil-platelet score (NPS) predicts survival in primary operable colorectal cancer and a variety of common cancers. PLOS ONE 10, e0142159 (2015).

5. Park, J. H., Watt, D. G., Roxburgh, C. S., Horgan, P. G. \& McMillan, D. C. Colorectal cancer, systemic inflammation, and outcome: staging the tumor and staging the host. Ann. Surg. 263, 326-336 (2016).
6. Fleming, I. D. American Joint Committee on Cancer, American Cancer Society. AJCC Cancer Staging Manual 5th edn (Lippincott Raven, Philadelphia, 1997).

7. Ishizuka, M. et al. Clinical significance of the c-reactive protein to albumin ratio for survival after surgery for colorectal cancer. Ann. Surg. Oncol. 23, 900-907 (2016).

8. Youden, W. J. Index for rating diagnostic tests. Cancer 3, 32-35 (1950).

9. Renfro, L. A. et al. Clinical calculator for early mortality in metastatic colorectal cancer: an analysis of patients from 28 Clinical Trials in the Aide et Recherche en Cancerologie Digestive Database. J. Clin. Oncol. 35, 1929-1937 (2017).

10. Sjoquist, K. M., et al. Personalizing survival predictions in advanced colorectal cancer: the ARCAD Nomogram Project. J. Natl. Cancer. Inst. (2017).

11. Dupre, A., Malik, H. Z. Inflammation and cancer: what a surgical oncologist should know. Eur. J. Surg. Oncol. (2018).

12. Rosales, C. Neutrophil: a cell with many roles in inflammation or several cell types? Front. Physiol. 9, 113 (2018).

13. Madden, K. S. Sympathetic neural-immune interactions regulate hematopoiesis, thermoregulation and inflammation in mammals. Dev. Comp. Immunol. 66, 92-97 (2017).

14. Park, J. H. et al. Staging the tumor and staging the host: a two centre, two country comparison of systemic inflammatory responses of patients undergoing resection of primary operable colorectal cancer. Am. J. Surg. (2017).

15. Nagtegaal, I. D. et al. Lymph nodes, tumor deposits, and TNM: are we getting better? J. Clin. Oncol. 29, 2487-2492 (2011).

16. Ueno, H. et al. Optimal colorectal cancer staging criteria in TNM classification. J. Clin. Oncol. 30, 1519-1526 (2012). 